\title{
Studi Geofisika Untuk Menentukan Batas Formasi Jampang dan Formasi Ciletuh di Kawasan Geopark Ciletuh
}

\author{
Cece Solihin $^{1}$, Arizal Taufik ${ }^{1}$, Firman Hadi Muhamad ${ }^{1}$, Rena Denya ${ }^{2}$ \\ ${ }^{1}$ Jurusan Fisika, Fakultas Sains dan Teknologi, Universitas Islam Negeri Sunan Gunung Djati \\ 2 Jurusan Pendidikan Fisika, Fakultas Tarbiyah dan Keguruan, Universitas Islam Negeri Sunan \\ Gunung Djati.
}

Jl. A. H. Nasution No 105 Cibiru Bandung Jawa Barat 40614

* Penulis Penanggungjawab. E-mail:solihincece0@gmail.com

Telp/hp: 088809408827

\begin{abstract}
ABSTRAK
Kawasan Ciletuh memiliki struktur geologi yang khas dan unik serta memiliki aneka ragam batuan yang tersebar. Pandangan umum dari ilmu kebumian kawasan ini sangat menarik untuk dipelajari karena geologi kawasan ini terbentuk tidak lepas dari aktivitas tektonik regional Jawa Barat. Studi geofisika sangat berguna dalam menganalisa struktur geologi bawah permukaan tanah di kawasan Ciletuh. Metode geofisika yang digunakan bertujuan untuk mengamati dan menganalisis struktur geologi batuan permukaan. Serta, tujuan utama dari penelitian ini untuk menentukan batas formasi Jampang dengan formasi Ciletuh. Penelitian ini digunakan pengambilan data dengan metode Geolistrik, Magnetik dan Ground Penetrating Radar (GPR) di daerah Tamanjaya, kawasan Ciletuh dengan lintasan yang berbeda. Berdasarkan interpretasi geolistrik pada software Res2Dinv 2D diperoleh struktur bawah permukaan berupa lapisan batuan pasir. Pada hasil interpretasi metode GPR pola perambatan serta kecepatan rambat gelombang elektromagnetik untuk dua lintasan GPR memiliki perbedaan struktur batuan yaitu batuan pasir kasar, kerikil dan endapan. Sedangkan hasil interpretasi magnetik mengindikasi perbedaan struktur batuan dalam bawah permukaan berdasarkan anomali magnetik. Berdasarkan geologi regional formasi Jampang bawah didominasi oleh batuan pasir halus. Sedangkan formasi Ciletuh didominasi oleh batuan pasir kasar yang berumur lebih tua. Sehingga batas formasi Jampang dengan batas formasi Ciletuh dapat diperkirakan pada lintasan GPR dan Magnetik.
\end{abstract}

Kata Kunci : Formasi Jampang; Formasi Ciletuh; Geolistrik; GPR dan Magnetik

31 | Copyright (C) 2017, Wahana Fisika, e-ISSN:2549-1989 


\begin{abstract}
The Ciletuh region has a distinctive and unique geological structure and also has a various of rocks scattered. The general view of the geography of this region is very interesting to learn because the geology of this region formed can not be sparated from the regional tectonic activity of west java. Geophysical studies are very useful in analyzing the subsurface geological structures in the Ciletuh region. The geophysical methods used aims to observe and analyze the geological structure of surface rocks. As well, the main purpose of this research is to determine the boundary of Jampang formation with Ciletuh formation. This research used data retrieval using Geoelectric, Magnetic and Ground Penetrating Radar (GPR) methods in Tamanjaya area, Ciletuh area with a different trajectory. Based on the geoelectric interpretation from Res2Dinv of software, there is obtained a subsurface structure in the form of sandstone layer. The results of the interpretation of GPR methods, propagation patterns and electromagnetic wave velocity for 2 trajectories have structural abnormalities, ie sandstone rock, gravel and sediment. Whereas the results of magnetic interpretation indicate difference in surface rocks structure based on magnetic anomlies. Base on the regional geology of the lower Jampang formation is dominated by fine sand rock while the formation of Ciletuh is dominated by Rugged Sandstone rocks that was older. So the boundary of formation Jampang with baoundary formations Ciletuh can be estimate at GPR and Magnetic trajectory.
\end{abstract}

Keywords : Jampang Formations; Ciletuh Formations; Geoeletric; GPR; and Magnetic

\section{Pendahuluan}

Daerah Ciletuh kabupaten Sukabumi Jawa Barat merupakan salah satu wilayah dari tiga wilayah di Pulau Jawa yang memiliki struktur geologi yang unik dengan tersingkapnya batuan tertua di Pulau Jawa [1]. Batuan tersebut merupakan batuan komplek yang mewakili batuan kerak Samudera diakibatkan oleh proses tektonik lempeng sehingga batuan tersebut terangkat ke permukaan Pulau Jawa.
Daerah Ciletuh berdasarkan stratigrafinya terdiri dari daratan Endapan Aluvial, Ultra Basa Gunung Beas, Komplek Melange, formasi Citirem, formasi Ciletuh dan formasi Jampang. Batas formasi Ciletuh dan formasi Jampang ditandai dengan bertemunya antara lembah Ciletuh dan dataran tinggi Jampang [2]. Kedua formasi ini memiliki struktur penyusun lapisan batuan yang berbeda. Oleh karena itu, untuk mengetahui informasi struktur 
geologi yang terdapat daerah tersebut maka perlu studi pengumpulan data lebih lanjut.

Suatu kegiatan pengumpulan data dan informasi geologi pada suatu daerah penelitian yang sering digunakan yaitu studi geofisika. Pengambilan data dengan metode geofisika sangat efektif untuk mengetahui struktur bawah permukaan tanah tanpa merusak lingkungan sekitar.

Pada kegiatan ini dilakukan tiga metode geofisika yaitu, metode geolistrik, metode magnetik dan metode Ground Penetrating Radar (GPR). Metode geolistrik merupakan salah satu metode geofisika yang mempelajari sifat aliran listrik di dalam bumi [3]. Sedangkan metode magnetik yaitu mengukur anomali medan magnet daerah penelitian yang didasarkan pada variasi intensitas medan magnetik permukaan bumi [4]. Untuk metode GPR merupakan metode pengukuran yang mempelajari kondisi bawah permukaan berdasarkan sifat elektromagnetik dengan menggunakan gelombang radio pada frekuensi tertentu [3]. Pengambilan data dengan metode geofisika ini bertujuan untuk mengamati dan menganalisis struktur geologi batuan bawah permukaan di wilayah Ciletuh. Serta tujuan utamanya yaitu mengetahui batas formasi jampang dan formasi Ciletuh pada daerah penelitian dengan menggunakan metode geolistrik, magnetik dan GPR.

\section{Bahan dan Metode Penelitian}

\subsection{Waktu Dan Tempat Penelitian}

Pada penelitian ini dilakukan di daerah Ciletuh, tepatnya desa Tamanjaya, kecamatan Ciemas, Kabupaten Sukabumi, Provinsi Jawa Barat yang dilaksanakan pada hari minggu 14 Mei 2017. Dalam pengambilan data ini dilakukan menggunakan metode Geolistrik, Magnetik dan GPR.

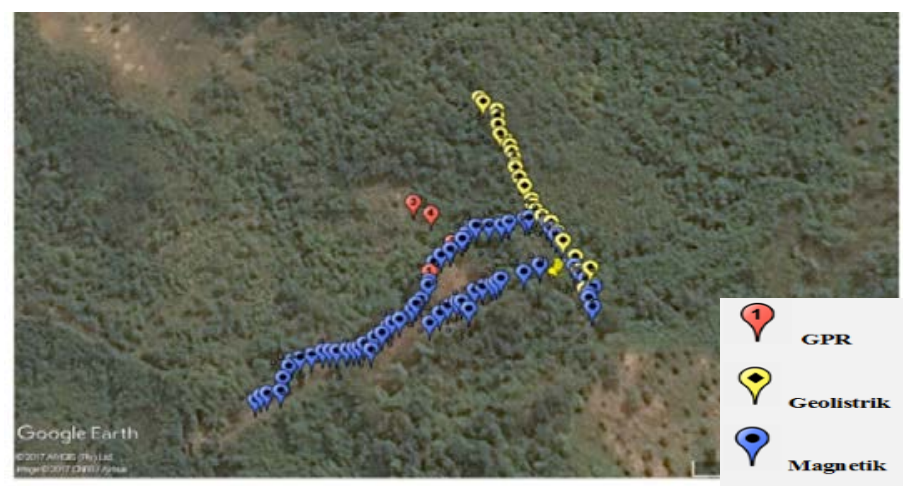

Gambar 2.1 Lokasi lintasan pengambilan data geolistrik, magnetik dan GPR 


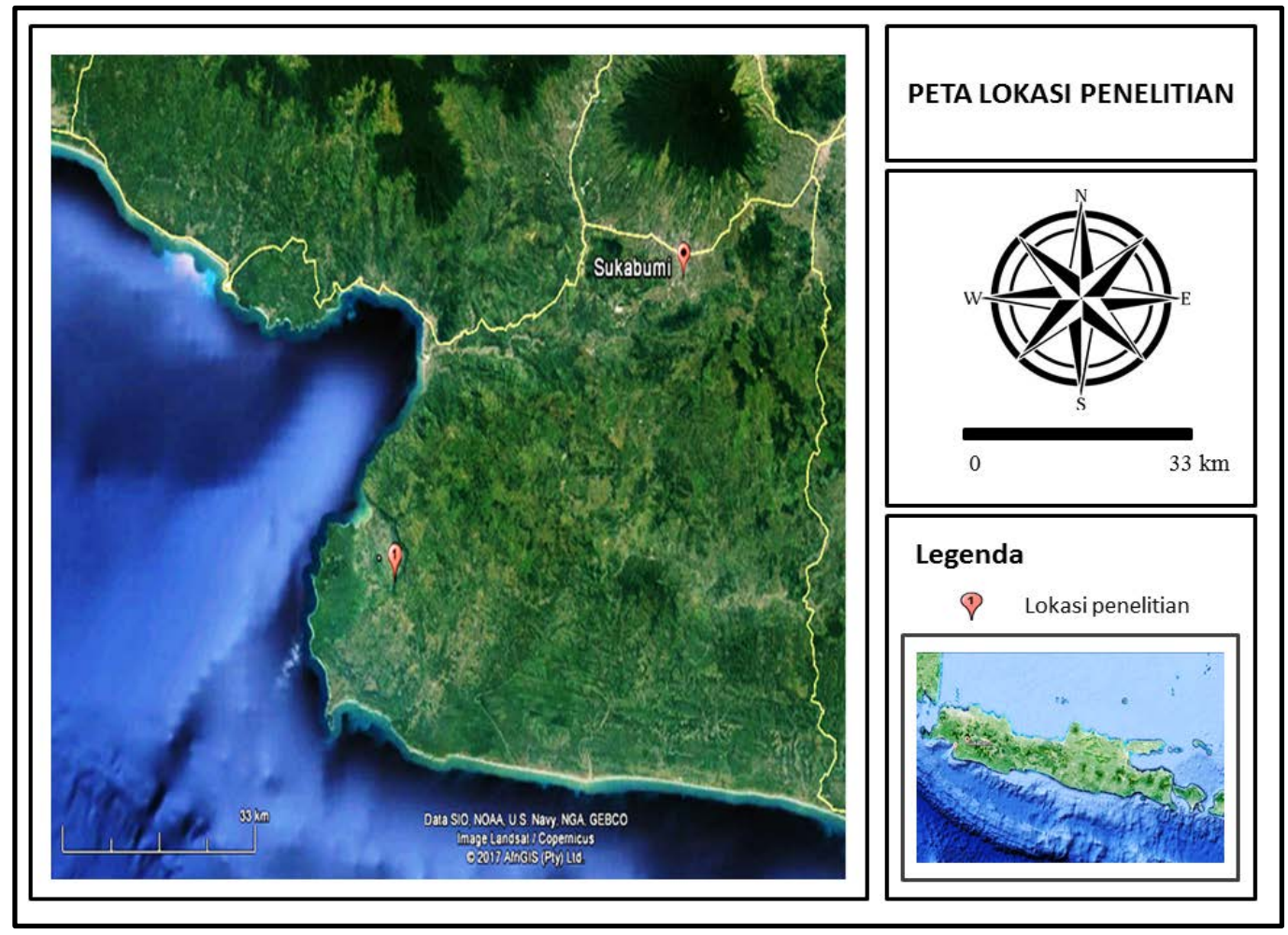

Gambar 2.2 Lokasi penelitian

\subsection{Metode Geolistrik}

\subsubsection{Akuisisi Data Metode}

\section{Geolistrik}

Pengukuran resistivitas ini dilakukan metode geolistrik konfigurasi wenner, lintasan pengukuran sepanjang 160 meter dengan jarak antar elektroda 5 meter sehingga pada lintasan ini memiliki 32 titik elektroda. Titik sounding dengan kordinat 106³0'3.16"BT 7¹4'37.34"LS pada titik awal dan koordinat 106³0'3.17"BT 7¹4'33.68"LS pada titik akhir dengan bentangan arah dari utara ke selatan.

Tiap-tiap elektroda dihubungkan ke alat geolistrik Masagi Multi-Chanel
Resistivity dengan kabel penghubung. Masagi Multi-Chanel Resistivity ini terdiri dari inverter, switch box (pengatur keluar masuknya tegangan dan arus) dan multimeter. Lalu Masagi Multi-Chanel Resistivity dihubungkan lagi dengan PC (Notebook). Setelah terhubung mulai diinjeksikan arus listrik searah (DC). Sehingga arus dan tegangan akan meuncul pada multimeter dan PC.

\subsubsection{Pengolahan Data Metode \\ Geolistrik}

Berdasarkan hasil akuisisi data geolistrik memberikan informasi berupa arus (I) dan tegangan (V). Pengolahan data dilakukan pada 
microsoft excel untuk mencari nilai resistivitas dari data yang diperoleh. Langkahnya yaitu dengan menghitung besar nilai resistansi, faktor geometri dan datumpoint. Setelah mengetahui nilai resistansi dan faktor geometrinya sehingga diperoleh besar nilai resitivitas [5].

Data yang diinput pada software Res2dinv yaitu nilai datumpoint, spasi elektroda dan resistivitas dengan ektensi file.dat. File tersebut diinversi dengan menggunakan software Res2Dinv untuk mengetahui sebaran nilai resistivitas dilokasi penelitian.

\subsection{Metode Magnetik}

\subsubsection{Akuisisi Data Metode Magnetik}

Dalam melakukan akuisisi data magnetik yang pertama dilakukan adalah menentukan base station dan membuat stasiun - stasiun pengukuran dengan jarak setiap station sepanjang 5 meter. Kordinat station pertama 106³0'3.22"BT $\quad 7^{\circ} 14$ '37.45"LS dan kordinat stasiun terakhir 106²9'57.54"BT $\quad$ 7¹4'39.66"LS. Pengukuran kuat medan magnet menggunakan magnetometer/ Proton Procession Magnetometer (PPM) G 856 AX sebanyak tiga kali disetiap stasiun [8]. Pada setiap stasiun tersebut ditentukan kordinatnya menggunakan GPS. Hasil setiap pengukuran dicatat dalam tabel pengukuran.

\subsubsection{Pengolahan Data Metode Magnetik}

Data lapangan yang diperoleh yaitu koordinat dan nilai magnetik disetiap stasiun. Data magnetik ini merupakan nilai magnetik observasi (Tobs). Kemudian untuk mengetahui nilai anomali magnetik totalnya dengan $\mathrm{T}$ IGRF dikurangi Tobs. $\mathrm{T}$ IGRF merupakan koreksi secara regional yang dilakukan terhadap data magnetik yang terukur untuk menghilangkan pengaruh medan utama magnet bumi [4]. T IGRF untuk daerah Ciletuh sebesar $44974.2 \mathrm{nT}$ yang dipreoleh dari situshttp://www.ngdc.noaa.gov/IAGA/ vmod/igrf.html.

Setelah melalui proses koreksi IGRF maka akan didapatkan nilai anomali magnetik total. Kemudian Plotting dilakukan pada software SURFER9. Dengan melakukan proses griding data pada software SURFER9, dimana data yang diinput merupakan kordinat latitude (sumbu-x), longitude (sumbuy) serta data anomali magnetiknya. 


\subsection{Metode Ground Penetrating Radar (GPR)}

\subsubsection{Akuisisi Data Metode GPR}

Dalam penggunaan metode GPR adalah sistem Electromagnetic Subsuface Profiling (ESP), dengan cara memanfaatkan pengembalian gelombang elektromagnet yang dipancarkan melalui permukaan tanah dengan prantara antena. Pemancaran dan pengembalian gelombang elektromaget berlangsung cepat sekali yaitu dalam satuan waktu nanosecond [6].

Alat yang digunakan GPR OKO-2 AB250M yang terdiri dari odometer, antena GPR, dan kontrol unit. Antena GPR memiliki frekuensi $250 \mathrm{MHz}$ dengan resolusi $0.25 \mathrm{~m}$ yang mampu melakukan penetrasi hingga kedalaman $\pm 8 \mathrm{~m}$. Sedangkan odometer berfungsi sebagai sensor kecepatan dan jarak. Dan Control Unit berfungsi untuk membangkitkan sinyal pemicu secara serempak transmitter dan receiver. Kemudian laptop, digunakan sebagai alat perekam digital penampang data
GPR yang dilengkapi dengan Software GeoScan32.

Langkah pengambilan data meliputi; memberikan tanda/marking menggunakan GPS pada lokasi lintasan pengambilan data. Pengambilan data dengan menghubungkan alat GPR OKO-2 AB-250M terhadap program GeoScan32 pada laptop. Pada saat program Geoscan32 dijalankan, alat juga dijalankan dengan cara didorong.

\subsubsection{Pengolahan Data Metode GPR}

Proses pengolahan data/prosesing GPR pada penelitian ini menggunakan software Reflexw meliputi tahapan proses pengoreksian posisi antenna transmitter dan receiver (Koreksi Statis), Proses peniadaan noise yang koheren (Substrack-mean), Gaining (Penguatan Amplitudo) merupakan proses pengubahan sinyal dan Filtering Data [7].

\section{Hasil dan Pembahasan}

\subsection{Hasil Interpretasi Data Metode Geolistrik}

Berikut hasil interpretasi data geolistrik menggunakan software Res2Dinv 


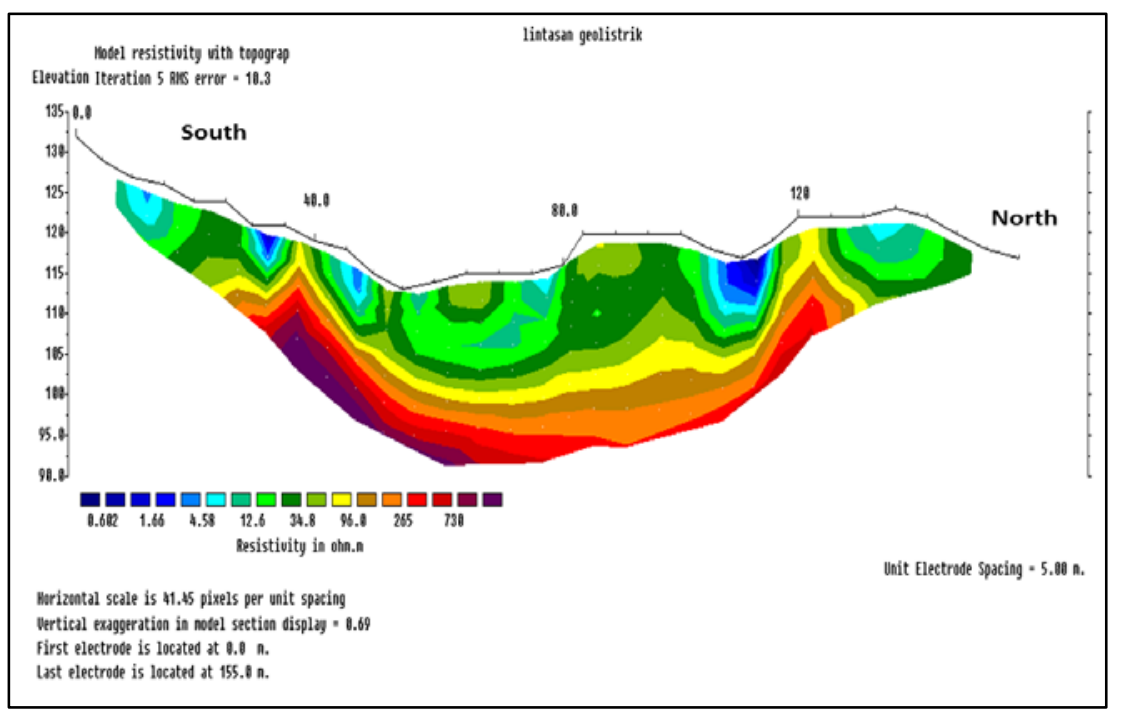

Gambar 3.1 Hasil penggambaran 2D lokasi penelitian

Hasil pengukuran data geolistrik diinterpretasikan pada Gambar 3.1. Berdasarkan hasil penampang diatas sebaran resistivitas pada lintasan tersebut

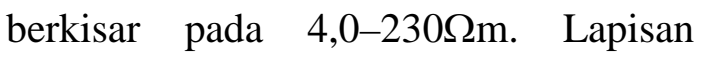
batuan pada bawah permukaan yang merujuk pada tabel resitivitas batuan [9] pada lintasan tersebut dapat diperkirakan bahwa lapisan batuan terdiri dari batuan lapuk dengan resistivitas yang kecil. Pada kedalaman 17-24 m, terdapat batuan dengan resistivitas lebih dari 178$230 \Omega \mathrm{m}$ dan diperkirakan lapisan tersebut merupakan batuan pasir yang merupakan komponen lapisan tanah dari formasi Ciletuh.

\subsection{Hasil Interpretasi Data Metode Magnetik}

Untuk memperoleh anomali magnetik total maka dilakukan koreksi untuk menghilangkan pengaruh medan magnet utama bumi dengan menggunakan nilai IGRF dimana IGRF daerah lokasi penelitian 44974.2nT pada posisi latitude dan longitude menggunakan metode kringing pada Software Surfer9 sehingga diperoleh seperti Gambar 3.2. 


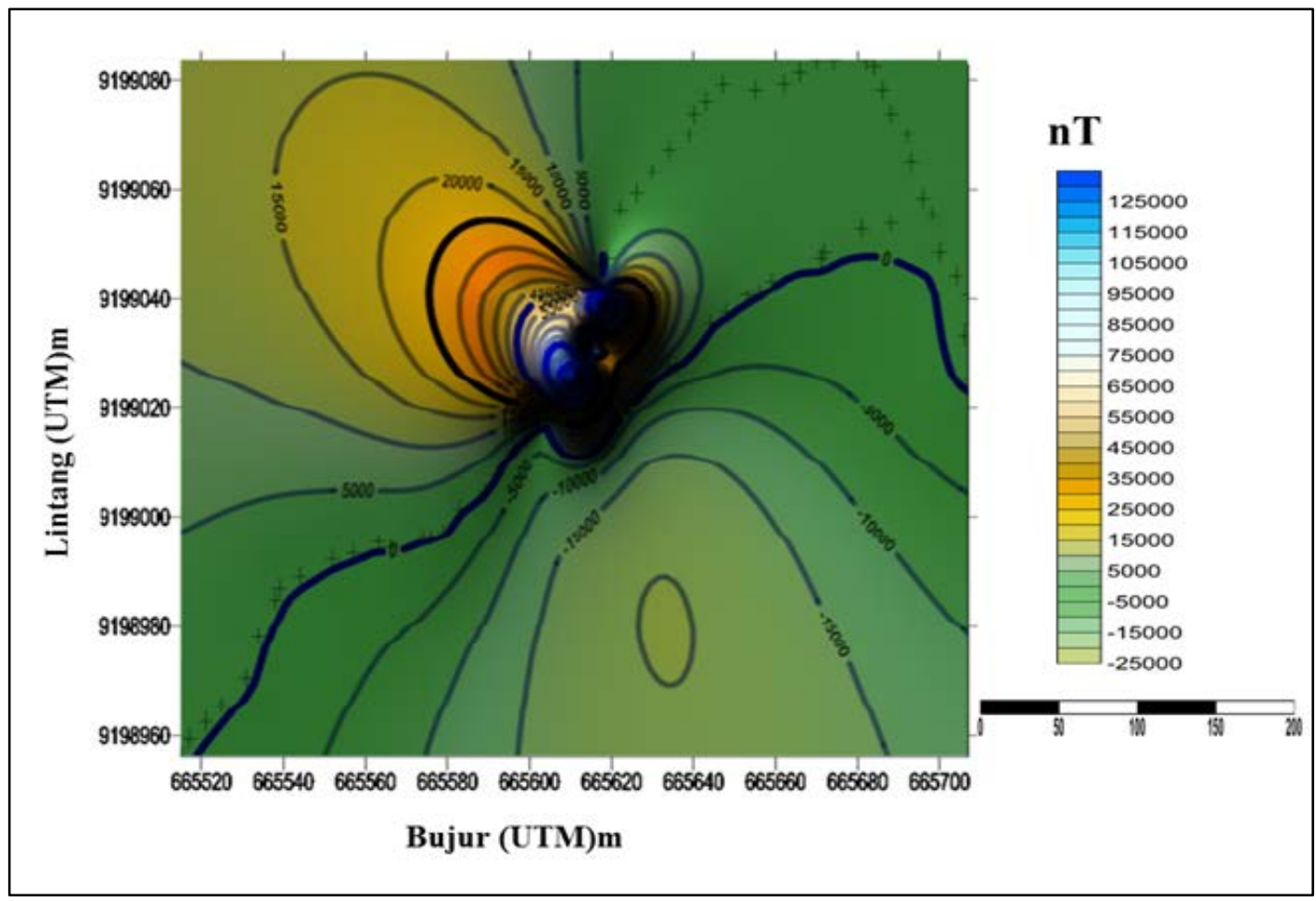

Gambar 3.2 Peta Kontur Anomali Magnet

Berdasarkan peta kontur anomali medan magnet total terlihat bahwa pola anomali dilokasi penelitian dengan anomali rendah 82.800nT pada kordinat 7.24351 latitude dan 106.5008 longitude, anomali sedang 236.500nT951.900nT dan anomali tinggi berkisar pada rentang 136735.333 nT dan 136801.133 nT.

Nilai anomali magnetik total tersebut terlihat dari perbedaan yang sangat jauh terhadap nilai medan magnet disekitar lokasi penelitian ditunjukan dengan kontras warna yang sangat terang. Perubahan anomali magnetik yang diduga karena terdapat batuan atau mineral yang berbeda disekitar lokasi penelitian yang membuat perubahan warna pada kontur, yang mana erat kaitannya dengan nilai suseptibilatas terhadap kandungan mineral didalam bumi. Perbedaan tersebut menandakan adanya perbedaan formasi batuan pada daerah penelitian yakni formasi Ciletuh dan formasi Jampang.

\subsection{Hasil Interpretasi Data Metode GPR}

Pemodelan interpretasi 2D didasarkan atas adanya kontras kecepatan pada radargram. Dari data radargram akan menunjukan suatu kemenerusan garis dari intensitas warna pada tampilan 
penampang yang merupakan citra dari kuat lemahnya amplitudo.

Berdasarkan profil GPR lintasan 1 pada kordinat $106^{\circ} 30^{\prime} 0.43$ "BT 7¹4'37.07"LS dan lintasan 2 pada kordinat $106^{\circ} 29^{\prime} 60.00^{\prime \prime B T}$ 7¹4'35.50"LS diperoleh zona perlapisan batuan yang berbeda .
Kontras kecepatan hasil picking pada masing-masing lapisan menandakan adanya perubahan jenis batuan dengan dilihat juga dari kontras amplitude picking (kecepatan berbanding lurus dengan amplitude gelombang). Sumbu vertikal pada profil GPR dinyatakan dengan waktu dan kedalaman.

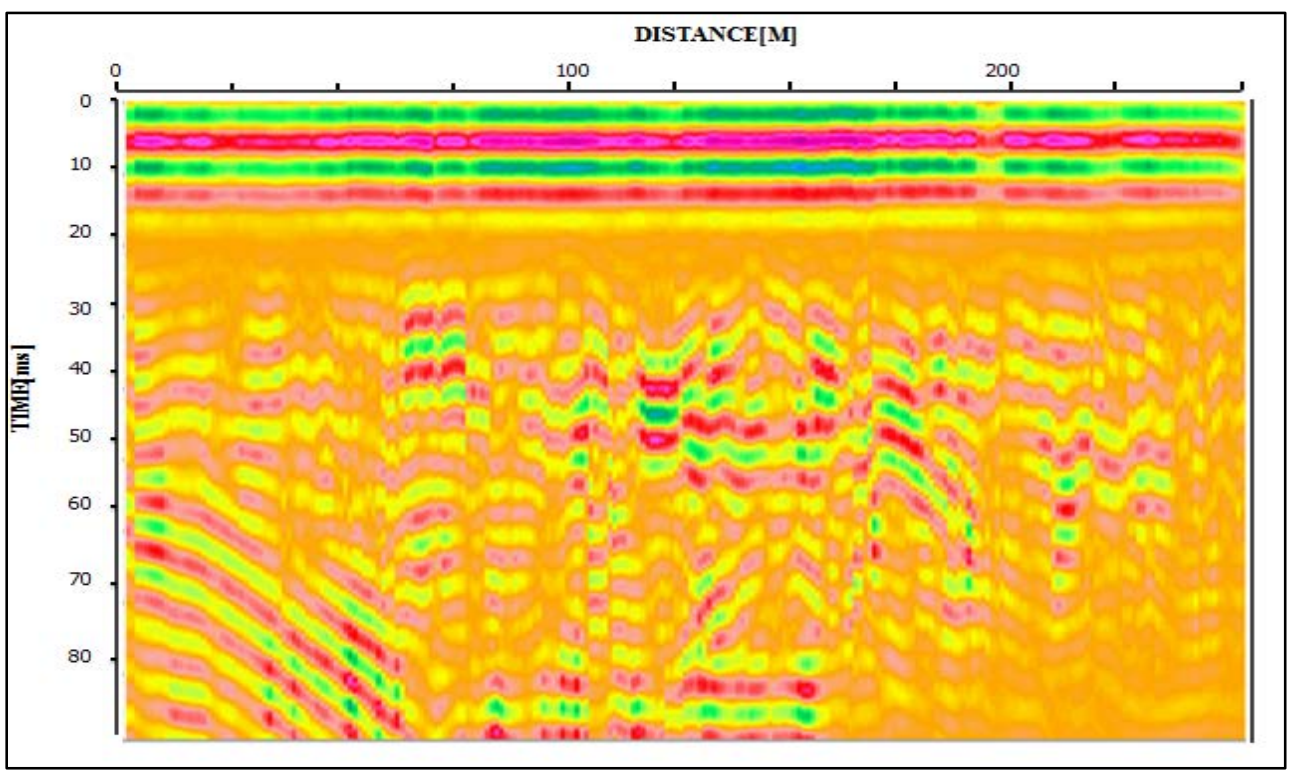

Gambar 3.3 Hasil Interpretasi Pada Software Reflexw Lintasan 1

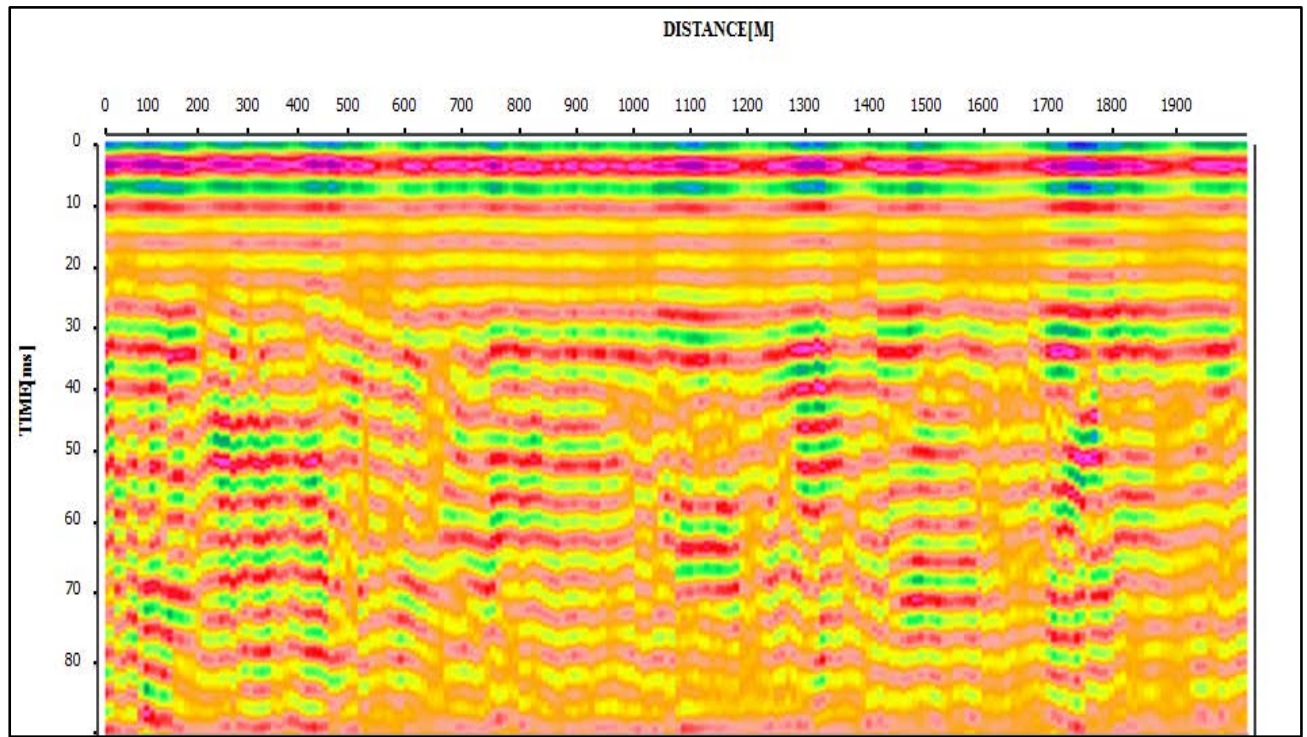

Gambar 3.4 Hasil Interpretasi Pada Software Reflexw Lintasan 2 
Dalam menentukan geologi bawah permukaan dari data georadar dengan menggunakan parameter penentuan tipe sedimen bawah permukaan [10] . Jika dilihat dari 2 lintasan diatas maka daerah penelitian tersebut diperoleh komponen penyusun lapisan bawah permukaan berupa pasir, bantalan, kerikil dan endapan. Pada lintasan 1 memiliki pola refleksi yang berbeda disepanjang lintasan pengukuran antara zona perlapisan atas dan perlapisan bawah yang mengindikasikan adanya perbedaan struktur batuan. Sedangkan pada lintasan 2 memiliki pola refleksi yang sama di sepanjang lintasan pengukuran yang diperoleh komponen lapisan batuan pasir kasar.

\section{Simpulan}

Hasil yang diperoleh berdasarkan pengambilan data menggunakan metode geofisika dapat disimpulkan bahwa batas formasi Ciletuh dan formasi Jampang teridentifikasi dari hasil interpretasi pada lintasan GPR dan terlihat pula pada hasil interpretasi anomali magnetik dilintasan tersebut.
Yang kemudian diperkuat dari anlisa studi geologi lokal pada daerah tersebut. Berdasarkan penelitian yang dilakukan dan hasil yang diperoleh penulis memberikan usulan dalam pengambilan data GPR frekuensi antena dari transmiter diperkecil agar jangkauan penetrasinya lebih dalam. Sedangkan pada metode magnetik sebaiknya dilakukan permodelan 2D untuk mendapatkan gambaran lebih detail mengenai struktur bawah permukaan tanah. Serta sebaiknya dilakukan pengukuran pada hasil bor agar mendapatkan kolerasi yang lebih akurat.

\section{Ucapan Terima Kasih}

Para penulis mengucapkan terimakasih kepada CV Massagi yang telah membantu dalam melaksanakan pengukuran dan pengambilan data serta sebagai penyedia alat geolistrik MultiChanel Resistivity

\section{Referensi}

1. Martodjojo, S., (1984). "Evolusi Cekungan Bogor Jawa Barat,” ITB.

2. Martodjojo, S., Suparka, S., and Hadiwisastra., (1978). “Status Formasi Ciletuh dalam Evolusi Jawa Barat,” Geologi. Indonesia., vol. 5, no. 2. 
3. Reynold, R. M., (1997).“An Introduction to Applied Geophysics,” England, John Wiley Sons, Inc.

4. Lita, F., (2012). “Identifikasi Anomali Magnetik di Daerah Prospek Panasbumi Arjuna Welirang,” Universitas Indonesia.

5. Supriyadi, Khumaedi, and Panca, R. N., (2013).“Pola Sebaran Limbah Tpa Studi Kasus di Jatibarang Semarang,” Jurnal FMIPA Univ. Negeri Semarang, vol. 20, no. 1, pp. 49-56, 2013.

6. Budiono, K., Handoko, Hermawan, U., and Godwin. (2010). "Penafsiran Struktur Geologi Bawah Permukaan di Kawasan Semburan Lumpur Sidoarjo Berdasarkan Penampang Ground Penetrating Radar ( GPR ),” jurnal Geologi. Indonesia., vol. 5, no. 3, pp. 187-195.

7. Fauziah, siti rofiqoh., (2016). "Metode Pengukuran Ground Penetrating Radar (GPR) Untuk Mendeteksi Pasir Besi di Daerah Pesisir Pantai Kulon Progo Jawa Tengah” UIN Bandung.

8. Santosa, Bagus jaya., Mashuri, Sutrisno, Wahyu., Wafi, R.A., Salim, and R. Armi, (2012). "Interpretasi Metode Magnetik Untuk Penentuan
Struktur Bawah Permukaan di Sekitar Gunung Kelud Kabupaten Kediri,” Jurnal Penelitian Fisika dan Aplikasi (JPFA) ITS, vol. 2, no. 1.

9. Hurun, N., (2016).“Analisis Data Geolistrik Resistivitas Untuk Pemodelan Struktur Geologi Bawah Permukaan Gunung Lumpur Bangkalan” Universitas Islam Negeri Maulana Malik Ibrahim Malang.

10. Beres, M., and Heani, P.F (1991). “Application of The Ground Penetrating Radar Methods in Hydrogeologi Studies” Ground Water, vol. 29, no. 3, pp. 375-386. 